\title{
Understanding the Pathological Stages of Peyronie's Disease and Treatment Options at Each Stage
}

\author{
Shady Emara* \\ Senior Clinical Fellow in Urology, East and North Hertfordshire Trust, Stevenage, UK \\ *Corresponding author: Shady Emara, East and North Hertfordshire Trust, Lister Hopsital, Stevenage, UK
}

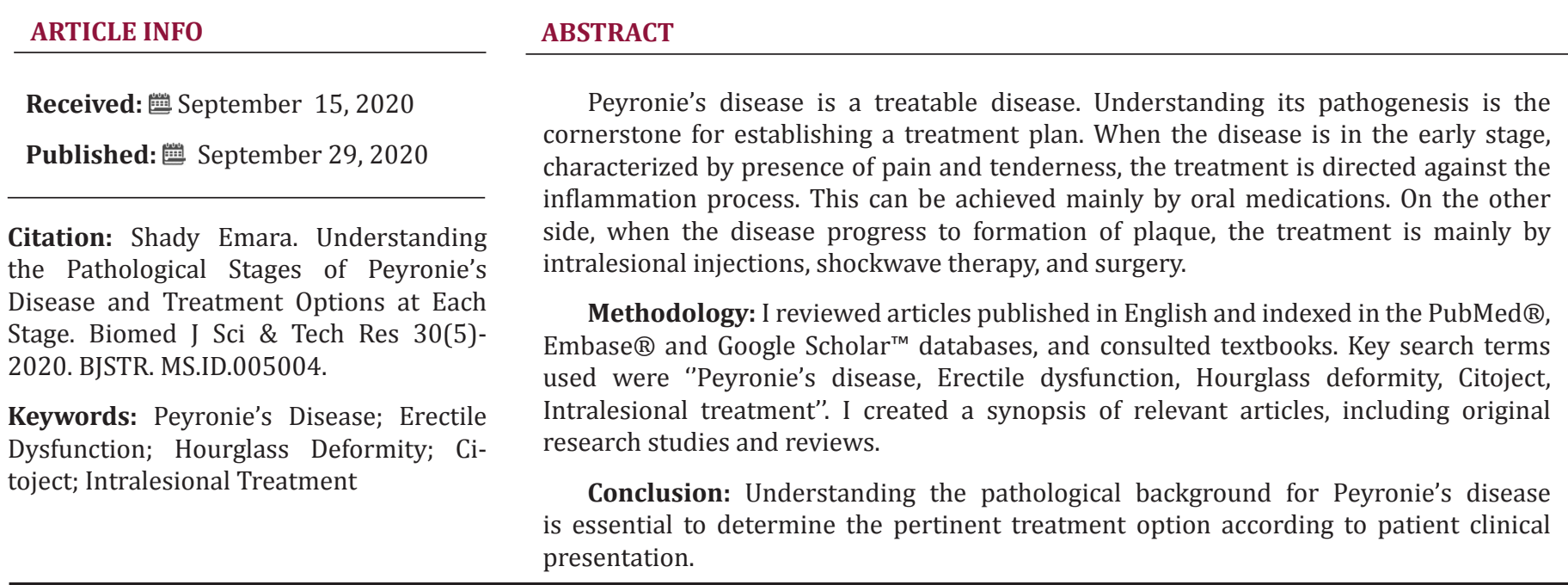

\section{Introduction}

Peyronie's disease affects elastic fibers located within the tunica albuginea of the penis. This leads to formation of an irregular framework upon which collagen rests. The elastic fibers in tunica albuginea is essential for penile erection as they allow both an increase in girth and length during tumescence [1]. Minor penile trauma that occur during sexual intercourse result in a delamination injury of the tunica albuginea mostly at the dorsal, midline septum. Minor trauma may have a role in the pathogenesis of Peyronie's disease [2]. Peyronie's plaques typically form a loose areolar connective tissue sleeve that separates the corpus cavernosum from the tunica albuginea[3]. In the early stage of this condition (usually less than 3 months), this sleeve contains a perivascular lymphocytic and plasmocytic inflammatory cellular infiltrate. After this early inflammatory phase, fibrosis occurs, and a thick connective tissue plaque is formed, and sometimes calcification occurs on top [4].

Electron microscopy evaluation of these plaques confirms a vasculitis in the tunica albuginea associated with mast cells, hence proving the role of inflammation[5]. Plaques were also found to be composed of type I and type III collagen fibers[6]. Somers et al found that penile scar tissue consists of both types I and III collagen fibers, whereas in Peyronie's plaques type III collagen was more abundant. In addition to this, increased type III collagen in the "normal" penile tissue adjacent to the plaque tissue suggests that this disease is not specific to the plaque but may be more generalized throughout the corporal tissues[7]. Furthermore, there is a significantly lower quantity of elastic fibers in impotent men with Peyronie's disease compared with Peyronie's patients who maintain potency. Antibodies to elastin are present in all individuals. However, Peyronie's patients have high levels of anti-trophoblastic (reflecting elastin synthesis) and anti-a-elastin (reflecting elastin destruction) [8].

\section{Natural History of Peyronie's Disease}

PD is a process of gradual spontaneous resolution[9]. Gelbard et al reported that $13 \%$ of the patients with PD will gradually resolve, $47 \%$ will remain stable, and $40 \%$ will worsen [10]. Certain features that predispose against spontaneous resolution include PD 
more than 2yr duration at presentation, presence of Dupuytren's contractures, plaque calcification, and curvature greater than $45^{\circ}$. Kadioglu and colleagues observed the natural course of PD in $63(20.5 \%)$ of 307 patients presenting with acute disease for a duration of 5.8 months and received no treatment. In this series, $30.2 \%$ of the patients reported progression of the deformity, and $66.7 \%$ had stable disease after a mean follow-up of 8.4 months with no treatment. Complete spontaneous resolution of the penile deformity was observed only in 2 cases in this group. In the chronic phase, which begins when disease duration is greater than 12 months, the deformity does not change during this stable period [11].

\section{Physical Examination}

Lumps can be seen and felt when the penis is flaccid state. However, to determine the extent of the bend, the penis needs to be erect. This can be done at office by injecting alprostadil in one side of penis, otherwise the patient can take photos for erect penis at home[12].

\section{Imaging Techniques}

An x-ray (By Mammography Technique): It shows any calcium deposits. About one third of patients with PD develop calcification, which indicates the end-stage of the disease, i.e the disease has run its full course and the lump is unlikely to worsen or change[13]. An ultrasound: It shows location, size, and shape of the plaque. Also, it detects encasement of the neurovascular bundle before surgical correction of the curvature to limit the risk of postoperative penile numbness[14]. Ultrasound detects encasement of the dorsal arteries when they are embedded in the plaque. Cavernosal artery encasement is observed in septal plaques, causing vasculogenic erectile dysfunction[15]. However, it is unreliable in distinguishing between active inflammatory and quiescent stages of the disease[16]. MRI of the penis: MRI is more sensitive in the detection of possible inflammatory change. Hence can be used in monitoring the effects of the therapy[17]. However, MRI examination of all patients presenting as Peyronie's disease would not be reasonable because of the rarity of malignant disease presenting in that manner. A high index of suspicion and low threshold should be there for investigating painless penile plaques/lumps that simulate Peyronie's disease, particularly in the elderly[18]. In these patients, timely MRI followed by corporal wedge biopsy might help reach an early diagnosis and offer curative treatment; such management should be considered earlier than is often the case, especially in older men with an atypical presentation[19].

Penile Scintigraphy with technetium Tc 99m human immunoglobulin G: Its advantage is that it provide a measurable parameter to help distinguish unstable PD, which is best treated medically, from stable PD, which may require surgical intervention. However, it needs a lot of refinement and accuracy[20].Duplex ultrasonography: If ED is associated with the PD, then duplex ultrasonography with intracavernous injections of a vasoactive agent, such as alprostadil, and/or dynamic infusion cavernosometry and cavernosography may be indicated to help identify associated arteriogenic ED or corporeal veno-occlusive dysfunction[21].Its role is to identify the extent of the Peyronie plaque, to evaluate for any hour-glass deformity in the shaft, and to quantify the extent and direction of penile angulation[22].

\section{Acu-Punch Biopsy}

Penile biopsy with Acu-Punch, such a low-invasive technique could be performed in all cases of Peyronie's disease and allows a more extensive use of microscopic analysis in the study of Peyronie's disease[23].

\section{Minimaly Invasive Treatment of Peyronie's}

Currently a plausible approach to the nonsurgical treatment of Peyronie's disease is combined therapy, which provide synergy between the oral, topical and intralesional drugs[24].

\section{Oral Therapy}

Vitamin E: Studies on the use of vitamin E in Peyronie's disease have shown a decrease in penile curvature in $78 \%$ of patients and a decrease in plaque size in 91\%[25]. Moreover, reports from American urologists showed that combination of vitamin $\mathrm{E}$ and colchicine could have some benefit in conservative treatment of $\mathrm{PD}[26]$.

Aminobenzoate Potassium: Potassium paraaminobenzoate appears to have both an anti-inflammatory and an anti-fibrotic effect due to stabilization of the tissue serotonin-monoamine oxidase activity and a direct inhibitory effect on fibroblast glycosamineglycane secretion[27]. Dose is $12 \mathrm{gm} /$ day as 6 capsules (500 mg each) every 4 hours. Side Effects include nausea, anorexia, pruritus, anxiety, chills, cold sweats, confusion, and difficulty in concentration, but no serious adverse events were reported[28].

Colchicine: Colchicine is an alkaloid derived from the autumn crocus, side effects include gastrointestinal upset, neutropenia, and peripheral neuropathy[29].

3.6.4.Tamoxifen \& N-acetyl Carnitine: Has been used to treat breast cancer with positive estrogen receptors. It may be helpful in Peyronie's treatment because of its modulation of TGFß expression[30].

Pentoxifylline (PTX), 3,7-dimetyl-1oxo-hexyl) xanthine: Is a nonspecific phosphodiesterase inhibitor, with combined antiinflammatory and antifibrogenic properties. PTX has been used in various human fibrotic conditions, including radiation proctitis, radiation-induced fibrosis, alcoholic hepatitis, and preventing atherosclerosis in hypertensive patients with type 2 diabetes mellitus[31].

L-arginine: L-arginine is an over-the-counter amino acid that is a precursor to nitric oxide and has been shown in vitro to 
have antifibrotic activity. Hence its value in treating patients who develop ED with peyronie's disease[32]. It acts through long-term inhibition of iNOS activity, presumably by blocking nitric oxide (NO)- and cGMP-mediated effects triggered by iNOS expression, exacerbates tissue fibrosis through an increase in: (a) collagen synthesis, (b) levels of reactive oxygen species (ROS), and (c) the differentiation of fibroblasts into myofibroblasts.The dosage is 500 mg twice a day[33].

\section{Local Therapy}

Intralesional injections is one of the most commonly used minimally invasive therapies for Peyronie's disease. A wide variety of agents in varying combinations have been used with generally good results[34].

\section{Verapamil}

\section{Route of administration}

a) Transdermal Iontophoresis

An effective treatment for pain control in early stages of Peyronie's disease, however efficacy in reducing penile curvature seems to be limited[35]. Iontophoresis (also known as transdermal electromotive drug administration-TEA or electromotive drug administration-EMDA) is the process whereby an electrical current utilizes the charges of a drug molecule to drive a pharmaceutical through the skin and into the region of interest and has the advantage of avoidance of first-pass metabolism, relative ease of use, and minimal side effects[36].

\section{b) Citoject}

Citoject syringe simultaneously delivers a high concentration of drug inside plaques and exerts a mechanical effect on them, has minimal side effects, and leads to minimal involvement of the tissues surrounding the plaque[37]. Verapamil is a calcium channel blocker that has been shown in in vitro studies to inhibit local extracellular matrix production by fibroblasts, to reduce fibroblast proliferation, to increase local collagenase activity, and to affect the cytokine milieu of fibroblasts[38]. Therapeutic serum levels of verapamil used for the treatment of hypertension and cardiac dysrhythmias range from 0.01 to $0.2 \mu \mathrm{M}$. However, the concentration to retard extracellular matrix collagen synthesis in their in vitro study was approximately $100 \mu \mathrm{M}$. As a consequence, direct delivery of the drug to the scar tissue was necessary to avoid toxic serum levels[39].

\section{c) Treatment Technique}

The penis is grasped at the level of the lesion, and a single puncture is performed. The needle is advanced into the plaque and the drugs are slowly injected. Once inside the plaque, the injected fluid forms a space between plaque's fibers. After the injection has been completed, patients are advised to hold pressure at the site of injection for 2 minutes to avoid the risk of hematoma[40].

\section{d) Evidence for Verapamil as a Treatment for PD}

Bennett et al. administered six intralesional injections (10 mg in $5 \mathrm{ml}$ ) every 2 weeks to 94 consecutive patients with PD. Follow up was at 5.2 months after completion of the sixth injection. Eighteen percent of the patients $(n=17)$ were found to have improved curvatures (average improvement 120), 60\% ( $n=56$ ) had stable curvature, and 22\% (n = 21) had increased curvature (average increase 22o). All patients with pretreatment penile pain had improvement at follow-up[41].

\section{Interferon}

Interferons are low molecular weight proteins and glycoproteins that are an important component of the immune system because of their antiproliferative effects[42]. Side effects include flu like symptoms, sinusitis , arthralgia[43].

\section{Collagenase Clostridium Histolyticum}

CollagenaseClostridium histolyticum is an enzyme produced by the bacterium Clostridium histolyticum that dismantles collagen. The substance is a constant mixture of two collagenases (AUX-I and AUX-II) with known amino acid sequences and a length of about 1000 amino acids each. It is prepared by anaerobic fermentation from a strain of C. histolyticum that has been known since 1950 [44]. In controlled trials, 98\% of patients treated with Xiaflex experienced an adverse reaction compared to 51\% treated with placebo. Common adverse reactions include peripheral edema, contusion, injection site hemorrhage, injection site reaction, and pain in the treated extremity. Serious effects that may occur with Xiaflex include allergic reactions, tendon rupture, or other serious injuries to the treated extremity. Flexor tendon rupture occurred in $0.3 \%$ of all treated patients[45]. No pharmacokinetic drug interactions have been described regarding Xiaflex. The efficacy and safety of Xiaflex have not been evaluated in patients receiving anticoagulants within seven days of Xiaflex administration with the exception of patients taking low-dose aspirin ( $<150 \mathrm{mg}$ daily). Use Xiaflex with caution in patients who are anticoagulated or who have coagulation disorders[46].

\section{Steroids}

Subcutaneous, nonintralesional injections of triamcinolone is an effective, safe, and durable means of managing severe, disabling, and/or chronic penile pain in patients with Peyronie disease[47]. Used with verapamil together in order to combine the anti-inflammatory effect of betamethasone, which leads to early resolution of plaque-related symptoms, and the anti-fibrotic effects of verapamil, which serves to prevent or reverse plaque growth[48].

\section{Extracorporeal Shock Wave Therapy (ESWT)}

Extracorporeal Shock Wave Therapy Extracorporal Shockwave Therapy (ESWT) has been utilized as a modality to treat Peyronie's disease since the late-1990s, with variable improvements in penile curvature, pain, and erectile function reported[49]. ESWT appears 
to have an effect on penile pain during erection and consequently, on the improvement of sexual function. Pain appears to resolve faster after ESWT than during the natural course of the disease. ESWT is thought to relieve pain either by the overstimulation or the direct destruction of nociceptors. It was suggested that ESWT may be beneficial to achieve freedom from pain within a short time. However, the question arises whether a symptom such as pain that resolves spontaneously with time should be treated by an expensive method such as ESWT[50].In Manikandan Study Patients received a minimum of 3 treatment sessions $(3,000$ shock waves at energy density of $0.3 \mathrm{~mJ} / \mathrm{mm} 2$ ), delivered either at intervals of 4 weeks or on consecutive days. After treatment, penile angulation was evaluated by autophotography. Patients were questioned about pain relief, but the study did not provide details on how this outcome was assessed. A total of $64 \%$ of patients reported that they had either excellent or significant improvement in penile angulation, while $36 \%$ said they had minimal or no improvement. Of those who had pain on erection before treatment, $84 \%$ reported complete or near complete relief after treatment[51].

\section{Effect on Erectile Dysfunction}

In Vardi study, Low-intensity extracorporeal shockwave therapy (LI-ESWT) was applied to the penile shaft and crura at five different sites. Assessment of erectile function was performed at screening and at 1 mo after the end of the two treatment sessions using validated sexual function questionnaires. LI-ESWT was found to be a promising treatment modality for ED[52]. Another study by Palmiere and colleagues aimed to assess the effects of extracorporeal shock wave therapy plus tadalafil $5 \mathrm{mg}$ once daily in the management of fresh cases of Peyronie's disease and erectile dysfunction. Main outcome measures were erectile function, pain during erection, plaque size, penile curvature, and quality of life . Follow-up evaluations were performed after 12 and 24 weeks. The result was a significantly higher mean International Index of Erectile Function score and quality of life score in patients receiving the combination[53].

\section{Radiation Therapy}

Though it may decrease pain, yet it has no effect on the plaque itself and can cause undesirable side effects[54].

\section{Penile Traction Therapy}

The Principle of Mechanical Traction: It mainly depends on cellular mitosis. When traction is applied to tissue, expansion occurs as an adaptive reaction. The same principle has successfully been applied for treating Dupuytren's contracture. It is possible, therefore, that the two conditions may share a common underlying pathophysiology, and therefore potentially respond to similar treatment modalities[55].

The Evidence for Penile Traction Therapy: Scroppo et al used PTT in patients with PD in a study of eight men. The inclusion criteria for the study involved all men with minimum 3 months of PD without concomitant ED and the men were instructed to use the traction device for at least $4 \mathrm{~h}$ a day for a total of 3-6 months. They reported an increase in the mean penile length of $4.1 \mathrm{~mm}(100.5 \mathrm{~mm}$ before and $104.6 \mathrm{~mm}$ after PTT) ( $\mathrm{p}>0.05)$ and decrease in mean erect penile curvature (EPC) of $14^{\circ}$ (from $34^{\circ}$ to $\left.20^{\circ}\right)(\mathrm{p}<0.05)$ in this small case series[56]. Colpi et al found that daily use of a penile traction device for $6 \mathrm{~h}$ a day in men with PD and severe penile retraction was associated with a longer Stretched Penile Length (SPL) (average $0.8 \mathrm{~cm}$ gain)[57]. Ideal patient characteristics for PTT include men with acute phase of PD or short penises, absence of calcified Peyronie's plaque, acceptable penile girth or absence of hour-glass penile deformity, normal erectile function, and finally highly motivated patient[58].

The Use of a Vacuum Erectile Device for Penile Length Preservation: VED functions through the creation of a vacuum around the penis, which leads to an erection by engorgement of penile tissue. The devices are easy to use, widely available, have few contraindications and require no testing prior to use[59]. Aghamir and colleagues reported that 6 months after VED use, there was a non-statistically significant increase in mean penile length from 7.6 to $7.9 \mathrm{~cm}[60]$. Raheem and colleagues found a clinically and statistically significant improvement in penile length, angle of curvature, and pain after 12 weeks of VED. However, there was no significant change in the sexual and erectile functions[61]. In Gontero study, the penile extender improved penile curvature with better results than that of intralesional injections. However, results were achieved in a selected population with stable disease[62]. The device caused minor side effects. Overall results were self-reported as "acceptable," making this minimally invasive treatment modality a potential new treatment option in selected Peyronie's disease patients[55].

\section{Conclusion}

Understanding the pathological background for peyronie's disease is essential to determine the pertinent treatment option according to patient clinical presentation.

\section{References}

1. Brock G, Hsu GL, Nunes L, Lue TF (1997) The Anatomy of the Tunica Albuginea in the Normal Penis and Peyronie's Disease. Journal of Urology 157(1): 276-281.

2. Sikka SC, Hellstrom WJ G (2002) Role of oxidative stress and antioxidants in Peyronie's disease. International Journal of Impotence Research 14(5): 353-360.

3. Campbell J, Alzubaidi R (2017) Understanding the cellular basis and pathophysiology of Peyronie's disease to optimize treatment for erectile dysfunction. Translational Andrology and Urology 6(1): 46-59.

4. Shioi A, Ikari Y (2018) Plaque Calcification During Atherosclerosis Progression and Regression. Journal of Atherosclerosis and Thrombosis 25(4): 294-303.

5. Springer JM, Raveendran VV, Gierer SA (2017) Protective Role of Mast Cells in Primary Systemic Vasculitis: A Perspective. Frontiers in Immunology 8: 990 
6. Walsh T, Ostrowski K, Gannon J (2016) A review of the epidemiology and treatment of Peyronie's disease. Research and Reports in Urology 8: 61.

7. Sommer F, Schwarzer U, Wassmer G, Bloch W, Braun M (2002) Epidemiology of Peyronie's disease. Int J Impot Res 14: 379-383.

8. Akkus E, Carrier S, Baba K (1997) Structural alterations in the tunica albuginea of the penis: impact of Peyronie's disease, ageing and impotence. BJU International 79: 47-53.

9. Kadioglu A, Küçükdurmaz F, Sanli O (2011) Current status of the surgical management of Peyronie's disease. Nature Reviews Urology 8(2): 95106.

10. Gelbard MK, James K, Riach P (1993) Collagenase Versus Placebo in the Treatment of Peyronie's Disease: A Double-blind Study. Journal of Urology 149: 56-58.

11. Kadioglu A, Sanli O Epidemiology of Peyronie's Disease. In: Peyronie'S Disease. Humana Press, pp. 9-18.

12. Pryor JP, Ralph DJ (2002) Clinical presentations of Peyronie's disease. International Journal of Impotence Research 14: 414-417.

13. Smith JF, Shindel AW, Huang YC (2010) Pentoxifylline treatment and penile calcifications in men with Peyronie's disease. Asian Journal of Andrology 13(2): 322-325

14. Kalokairinou K, Konstantinidis C, Domazou M (2012) US Imaging in Peyronie's Disease. Journal of Clinical Imaging Science 2: 63.

15. Fernandes MAV, Souza LRMF de, Cartafina LP (2018) Ultrasound evaluation of the penis. Radiologia Brasileira 51: 257-261.

16. Helweg G, Judmaier W, Buchberger W (1992) Peyronie's disease: MR findings in 28 patients. American Journal of Roentgenology 158(6): 1261-1264

17. Helweg G, Judmaier W, Wicke K (1992) Ultrasound and MRI in the diagnosis of penile induration (Peyronie's Disease). European Radiology 2: $230-232$.

18. Hurrell C (2012) Primary Penile Cancer + Peyronie's Disease = Diagnostic Difficulty: A Case of Delayed Diagnosis with a Review of the Problem of Penile Neoplasms Masquerading as, or Being Masked by, Peyronie's Disease. The Open Urology \& Nephrology Journal 5: 24-27.

19. Ung JO, Padera RF, O leary MP (2002) Angiosarcoma of the penis masquerading as a Peyronie’s plaque. JUrol 167(4): 1785-1786.

20. Chen JY, Hockenberry MS, Lipshultz LI (2018) Objective Assessments of Peyronie's Disease. Sexual Medicine Reviews 6(3): 438-445.

21. Levine L (2006) Peyronie's disease and erectile dysfunction: Current understanding and future direction. Indian Journal of Urology 22(3): 246.

22. Chung E, De Young L, Brock GB (2011) Penile Duplex Ultrasonography in Men with Peyronie's Disease: Is it Veno-Occlusive Dysfunction or Poor Cavernosal Arterial Inflow that Contributes to Erectile Dysfunction? The Journal of Sexual Medicine 8(12): 3446-3451.

23. Mirone V (2002) A New Biopsy Technique to Investigate Peyronie's Disease Associated Histologic Alterations: Results with Two Different Forms of Therapy. European Urology 42: 239-244

24. Randhawa K, Shukla CJ (2019) Non-invasive treatment in the management of Peyronie's disease. Therapeutic Advances in Urology 11: 175628721882367.

25. Paulis G, Romano G, Paulis L (2017) Recent Pathophysiological Aspects of Peyronie's Disease: Role of Free Radicals, Rationale, and Therapeutic Implications for Antioxidant Treatment-Literature Review. Advances in Urology 2017: 1-17.

26. Cortés González JR, Glina S (2010) Conservative treatment of Peyronie's disease: Colchicine vs. colchicine plus vitamin E. Actas Urológicas Españolas (English Edition) 34(5): 444-449.
27. Weidner W, Hauck EW, Schnitker J (2005) Potassium Paraaminobenzoate $\left(\right.$ POTABA $^{\mathrm{TM}}$ ) in the Treatment of Peyronie's Disease: A Prospective, Placebo-Controlled, Randomized Study. European Urology 47: 530-536.

28. Gur S, Limin M, Hellstrom WJ (2011) Current status and new developments in Peyronie's disease: medical, minimally invasive, and surgical treatment options. Expert Opinion on Pharmacotherapy 12: 931-944.

29. Finkelstein Y, Aks SE, Hutson JR (2010) Colchicine poisoning: the dark side of an ancient drug. Clinical Toxicology 48(5): 407-414.

30.Vendrell JA, Robertson KE, Ravel P (2008) A candidate molecular signature associated with tamoxifen failure in primary breast cancer Breast Cancer Research 10(5).

31. Nidhyanandan S, Boreddy TS, Chandrasekhar KB (2015) Phosphodiesterase inhibitor, pentoxifylline enhances anticancer activity of histone deacetylase inhibitor, MS-275 in human breast cancer in vitro and in vivo. European Journal of Pharmacology 764: 508-519.

32. Barrett Harlow B, Wang R (2016) Oral therapy for Peyronie's disease, does it work? Translational Andrology and Urology 5: 296-302.

33. Valente EG, VernetD, Ferrini MG(2003) l-Arginine and phosphodiesterase (PDE) inhibitors counteract fibrosis in the Peyronie's fibrotic plaque and related fibroblast cultures. Nitric Oxide 9(4): 229-244.

34. Chong W, Tan RBW (2016) Injectable therapy for Peyronie's disease. Translational Andrology and Urology 5: 310-317.

35. Cabello Benavente R, Moncada Iribarren I, de Palacio España A (2005) Iontoforesis transdérmica con dexametasona y verapamilo para la Enfermedad de La Peyronie. Actas Urológicas Españolas 29: 955-960.

36. Montorsi F, Salonia A, Guazzoni G, Barbieri L, Colombo R, et al. (2000) Transdermal electromotive multi-drug administration for Peyronie's disease: Preliminary results. Journal of Andrology 21(1): 85-90.

37. Zucchi A, Perovic S, Costantini E, Mearini L, Fioretti F (2010) Intraplaque injection of betamethasone and verapamil using a new plunger mechanism syringe with ergonomic leverage handling for the treatment of Peyronie's disease. Journal of Andrological Sciences 17(1).

38. Tsambarlis P, Levine LA (2018) Nonsurgical management of Peyronie's disease. Nature Reviews Urology 16: 172-186.

39. Levine LA, Estrada CR (2002) Intralesional verapamil for the treatment of Peyronie's disease: a review. International Journal of Impotence Research 14: 324-328.

40. Rehman J, Benet A, Melman A (1998) Use of Intralesional Verapamil to Dissolve Peyronie's Disease Plaque: A Long-Term Single-Blind Study. Urology 51: 620-626.

41. Bennett NE, Guhring P, Mulhall JP (2007) Intralesional Verapamil Prevents the Progression of Peyronie's Disease. Urology 69: 1181-1184.

42. Lin F, Young HA (2014) Interferons: Success in anti-viral immunotherapy. Cytokine \& Growth Factor Reviews 25(4): 369-376.

43. Sleijfer S, Bannink M, Gool AR (2005) Side Effects of Interferon- $\alpha$ Therapy. Pharmacy World \& Science 27: 423-431.

44. Clyne MC (2012) C. histolyticum collagenase effective against Peyronie. Nature Reviews Urology 9: 296-296.

45. Egui Rojo MA, Moncada Iribarren I, Carballido Rodriguez J (2014) Experience in the use of collagenase clostridium histolyticum in the management of Peyronie's disease: current data and future prospects. Therapeutic Advances in Urology 6(5): 192-197.

46. (2013) XIAFLEX(collagenase clostridium histolyticum) for injection, for intralesional use [prescribing information] Chesterbrook, PA: Auxilium Pharmaceuticals, Inc

47. Dickstein R, Uberoi J, Munarriz R (2009) Severe, Disabling, and/or Chronic Penile Pain Associated with Peyronie Disease: Management 
with Subcutaneous Steroid Injection. Journal of Andrology 31(15): 445449.

48. Ghoreifi A, Asadpour A, Hajian, S (2015) Intralesional Injection Therapy for Peyronie's Disease: Verapamil versus Triamcinolone. Conference Paper. 33rd World Congress of Endourology \& SWL

49. Di Mauro M, Russo GI, Della Camera PA (2019) Extracorporeal Shock Wave Therapy in Peyronie's Disease: Clinical Efficacy and Safety from a Single-Arm Observational Study. The World Journal of Men's Health 37: 339.

50. Hauck EW, Mueller UO, Bschleipfer T (2004) Extracorporeal Shock Wave Therapy for Peyronie's Disease: Exploratory Meta-Analysis of Clinical Trials. Journal of Urology 171: 740-745.

51. Manikandan R, Islam W, Srinivasan V (2002) Evaluation of extracorporeal shock wave therapy in Peyronie's disease. Urology 60: 795-799.

52. Vardi Y, Appel B, Jacob G (2010) Can Low-Intensity Extracorporeal Shockwave Therapy Improve Erectile Function? A 6-Month Follow-up Pilot Study in Patients with Organic Erectile Dysfunction. European Urology 58: 243-248.

53. Palmieri A, Imbimbo C, Creta M (2011) Tadalafil once daily and extracorporeal shock wave therapy in the management of patients with Peyronie's disease and erectile dysfunction: results from a prospective randomized trial. International Journal of Andrology 35: 190-195.

54. Mulhall JP, Hall M, Broderick GA (2012) Radiation Therapy in Peyronie's Disease. The Journal of Sexual Medicine 9(5): 1435-1441.

ISSN: 2574-1241

DOI: $10.26717 /$ BJSTR.2020.30.005004

Shady Emara. Biomed J Sci \& Tech Res

(C) (i) This work is licensed under Creative

Submission Link: https://biomedres.us/submit-manuscript.php
55. Chung E, Brock G (2012) Penile traction therapy and Peyronie's disease: a state of art review of the current literature. Therapeutic Advances in Urology 5: 59-65.

56. Scroppo F, Mancini M, Maggi M, Colpi G (2001) Can an external penis stretcher reduce Peyronie's penile curvature? Int J Impot Res 13(Suppl 4): S21.

57. Colpi G, Martini P, Scroppo F, Mancini M, Castiglioni F (2002) Efficacy of daily penis stretching technique to elongate the small penis. Int J Impot Res 14(Suppl 4): S73.

58. Valenzuela R, Ziegelmann M, Tokar S (2019) The use of penile traction therapy in the management of Peyronie's disease: current evidence and future prospects. Therapeutic Advances in Urology 11: 175628721983813

59. Lehrfeld T, Lee DI (2009) The role of vacuum erection devices in penile rehabilitation after radical prostatectomy. International Journal of Impotence Research 21: 158-164.

60. Aghamir MK, Hosseini R, Alizadeh F (2006) A vacuum device for penile elongation: fact or fiction? BJU International 97: 777-778.

61. Raheem AA, Garaffa G, Raheem TA (2010) The role of vacuum pump therapy to mechanically straighten the penis in Peyronie's disease. BJU International 106: 1178-1180.

62. Gontero P, Di Marco M, Giubilei G (2009) Peyronie's disease: Use of Penile Extender Device in the Treatment of Penile Curvature as a Result of Peyronie's Disease. Results of a Phase II Prospective Study. The Journal of Sexual Medicine 6: 558-566.

$\begin{array}{ll}\text { BIOMEDICAL } & \text { Assets of Publishing with us } \\ \text { RESEARCHES } & \text { Global archiving of articles } \\ \text { - Immediate, unrestricted online access } & \text { - Rigorous Peer Review Process } \\ & \text { - Authors Retain Copyrights } \\ & \text { https://biomedres.us/ }\end{array}$

